\title{
Trauma Computed Tomography: Benefits and Hazards
}

\author{
Shahram Paydar · Behnam Dalfardi
}

Published online: 22 May 2014

(c) Société Internationale de Chirurgie 2014

\section{To the Editor,}

With much interest and attention, we read the paper of Sierink et al. [1] in the April 2014 issue of the World Journal of Surgery. In that article, based on the study results-i.e., lower 30-day mortality rate among patients who underwent immediate total-body computed tomography (TBCT) compared with those evaluated with conventional imaging followed by selective CT scans-the authors defended the role of immediate TBCT in the acute trauma care setting. It seems fair to note some points.

Despite its advantage, the routine use of immediate TBCT to evaluate trauma patients can expose them to unnecessary doses of radiation, consequently putting them at a probable increased risk of cancer [2]. Another major concern associated with contrast-enhanced CT is contrast-induced nephropathy, a main cause of hospital-acquired acute renal injury [3].

From the aspect of the time used to assess the patients, the authors criticized the use of X-ray imaging in trauma cases. However, it should be noted that selective use of conventional cervical, chest, or pelvic imaging instead of routine radiography for all patients can be significantly time saving $[4,5]$. In this respect, a review of the literature turned up

S. Paydar

Department of General Surgery, Shiraz University of Medical Sciences, Shiraz, Iran

S. Paydar

Trauma Research Center, Shahid Rajaee (Emtiaz) Trauma

Hospital, Shiraz University of Medical Sciences, Shiraz, Iran

B. Dalfardi $(\bowtie)$

Student Research Committee, Shiraz University of Medical

Sciences, Shiraz, Iran

e-mail: dalfardibeh@gmail.com several articles regarding efforts made to develop some criteria for the use of selective radiography in trauma cases.

Transferring trauma patients between the admission ward and the CT room is yet another difficulty associated with the routine use of immediate TBCT in these cases. In addition, such an approach can increase health care costs for the patients and can lead to an increase in the costs associated with the use of technical personnel and those that result from the inevitable wear and tear of the equipment. Another negative point is that long-term use of routine immediate TBCT probably affects the quality of surgeons' skills in history taking and physical examination of trauma patients. It also may lead to findings of questionable clinical importance $[4,5]$.

Finally, it should be remembered that $\mathrm{CT}$ is not available in all regions of the world. Also, in conditions such as a disaster, the increased number of trauma patients can affect the availability of the use of CT. Therefore, the need for alternative approaches in the acute trauma care setting is still present.

\section{References}

1. Sierink JC, Saltzherr TP, Beenen LF et al (2014) A case-matched series of immediate total-body CT scanning versus the standard radiological work-up in trauma patients. World J Surg 38:795-802. doi:10.1007/s00268-013-2310-4

2. Brenner DJ, Elliston CD (2004) Estimated radiation risks potentially associated with full-body CT screening. Radiology 232:735-738

3. Gleeson TG, Bulugahapitiya S (2004) Contrast-induced nephropathy. AJR Am J Roentgenol 183:1673-1689

4. Hoffman JR, Mower WR, Wolfson AB et al (2000) Validity of a set of clinical criteria to rule out injury to the cervical spine in patients with blunt trauma: National Emergency X-Radiography Utilization Study Group. N Engl J Med 343:94-99

5. Plurad D, Green D, Demetriades D et al (2007) The increasing use of chest computed tomography for trauma: is it being overutilized? J Trauma 62:631-635 